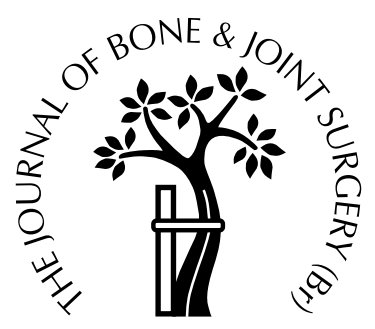

\title{
Contamination during removal of cement in revision hip arthroplasty
}

\section{A CADAVER STUDY USING ULTRASOUND AND HIGH-SPEED CUTTERS}

\author{
M. Nogler, C. Lass-Flörl, C. Wimmer, E. Mayr, C. Bach, M. Ogon \\ From the University of Innsbruck, Austria
}

I nstruments used in surgery which rotate or vibrate at a high frequency can produce potentially contaminated aerosols. Such tools are in use in cemented hip revision arthroplasties. We aimed to measure the extent of the environmental and body contamination caused by an ultrasound device and a high-speed cutter.

On a human cadaver we carried out a complete surgical procedure including draping and simulated blood flow contaminated with Staphylococcus aureus (ATCC 12600). After cemented total hip arthroplasty, we undertook repeated extractions of cement using either an ultrasound device or a high-speed cutter. Surveillance cultures detected any environmental and body contamination of the surgical team.

Environmental contamination was present in an area of $6 \times 8 \mathrm{~m}$ for both devices. The concentration of contamination was lower for the ultrasound device. Both the ultrasound and the high-speed cutter contaminated all members of the surgical team. The devices tested produced aerosols which covered the whole operating theatre and all personnel present during the procedure. In contaminated and infected patients, infectious agents may be present in these aerosols. We therefore recommend the introduction of effective measures to control infection and thorough disinfection of the operating theatre after such procedures.

J Bone Joint Surg [Br] 2003;85-B:436-9.

Received 21 May 2001; Accepted after revision 6 September 2002

M. Nogler, MD, MA, Associate Professor

C. Wimmer, MD, Associate Professor

E. Mayr, MD, Resident

C. Bach, MD, Associate Professor

M. Ogon, MD, Associate Professor

Department of Orthopaedic Surgery

C. Lass-Flörl, MD, Associate Professor

Department of Hygiene

University of Innsbruck, Anichstrasse 35, A-6020-Innsbruck, Austria.

Correspondence should be sent to Dr M. Nogler.

(C)2003 British Editorial Society of Bone and Joint Surgery doi:10.1302/0301-620X.85B3.12451 \$2.00
Recent studies have shown that high-speed cutters in primary hip arthroplasty and spinal surgery can produce aerosols. ${ }^{1-3}$ These aerosols, possibly contaminated with bacterial, fungal or viral agents, are spread over the operating room and contaminate the environment and all personnel present during the surgical procedure. There is also a risk of infection through contact with mucous membranes or small wounds or by inhalation for both health-care workers and other patients. ${ }^{4,5}$

In revision hip arthroplasty, different tools and highspeed cutters are used for removal of cement from the femoral cavity, particularly ultrasound devices, which vibrate at a high frequency. ${ }^{6}$ These devices also produce aerosols consisting of a mixture of irrigation solution, blood, tissue debris and body fluids.

Our aim therefore was to measure the environmental and body contamination caused by an ultrasound device and a hand-guided high-speed cutter used for removal of cement from the femoral cavity.

\section{Materials and Methods}

We carried out cemented arthroplasty on the left hip of a male human cadaver through an anterolateral transgluteal approach. With the cadaver supine, implantation and removal of a Lubinus SPII stem (LINK, Hamburg, Germany) left a typical cement mantle in the femoral cavity. A complete surgical procedure involved routine draping and the use of a $170 \mathrm{~cm}$ high drape barrier separating the operating table from the anaesthetist. All personnel present during the tests, which included an anaesthetist, a surgeon (sitting on the left side), an assistant (on the right side) and one scrub nurse (beside the cadaver's legs on the left side) wore water-resistant sterile surgical gowns, gloves, caps and Fluidmasks (Tecnol, Fort Worth, Texas) covering the whole face. The operating room had no air-filtration system. The cement was extracted using either a high-speed cutting device with a $6 \mathrm{~mm}$ ball cutter (Ultra Power System; Zimmer, Warsaw, Indiana) or an ultrasound device (Ultradrive; Biomet, Warsaw, Indiana). Extraction with each device took 35 minutes. After each test, all draping and clothing were removed and replaced. We then repeated (three times for each device) the implantation and removal of the implant, thereby renewing the cement mantle. 


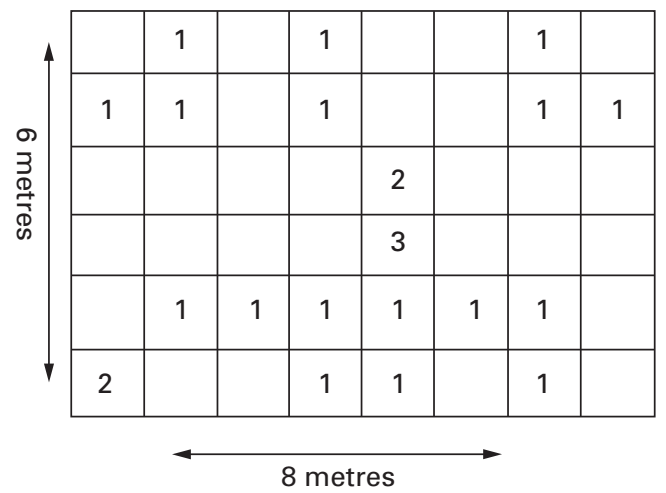

$95 \% \mathrm{Cl} 0.3$ to 0.7

\begin{tabular}{|c|c|c|c|c|c|c|c|}
\hline 9 & 16 & 31 & 26 & 22 & 29 & 13 & 12 \\
\hline 14 & 6 & 26 & 29 & 24 & 35 & 8 & 6 \\
\hline 15 & 12 & 27 & 23 & 25 & 26 & 11 & 8 \\
\hline 28 & 20 & 12 & 12 & 9 & 12 & 14 & 10 \\
\hline 5 & 3 & 9 & 9 & 7 & 8 & 9 & 6 \\
\hline 15 & 24 & 20 & 9 & 14 & 1 & 12 & 12 \\
\hline
\end{tabular}

$95 \% \mathrm{Cl} 12.8$ to 17.7

Fig. 1

Median CFU units in all sectors of the room for the detection of environmental contamination for a) the ultrasound device and b) the high-speed cutter with $95 \%$ CIs of medians.

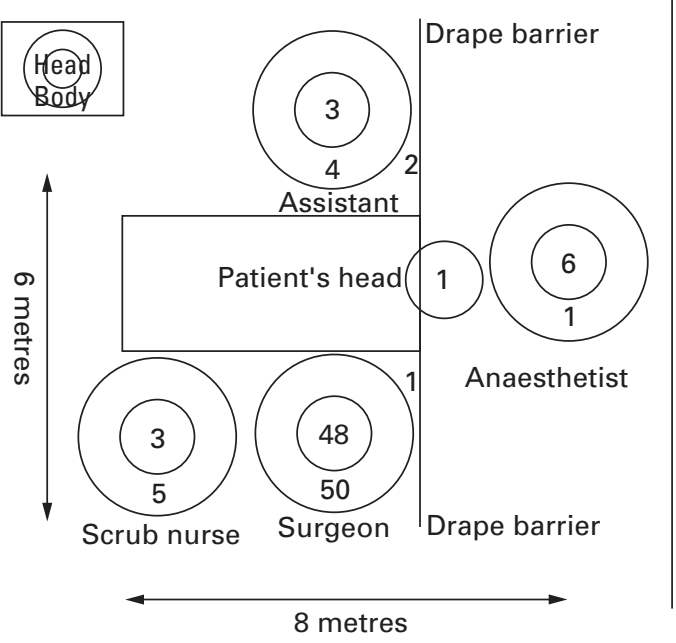

b

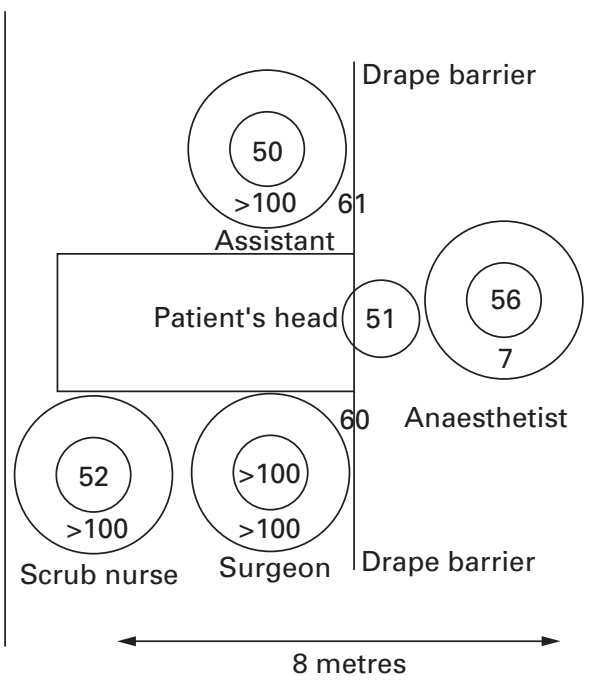

Fig. 2

Median CFU counts for body contamination of the surgical time for a) the ultrasound device and b) the high-speed cutter with $95 \%$ CIs.

We placed two needles in vastus lateralis over the exposed femur in order to stimulate blood flow in the surrounding soft tissue. Another needle was introduced into the femoral cavity through a hole drilled after implantation in order to simulate intramedullary bleeding. The needles were connected to a 1.51 reservoir containing a saline solution contaminated with Staphylococcus aureus (American Type Culture Collection, ATCC 12600). Determination of the final concentration of colony-forming units (CFUs) was after growth in tryptic soy broth (Merck, Darmstadt, Germany) under aerobic conditions at $37^{\circ} \mathrm{C}$ for 24 hours and then incu- bation on columbia blood agar (Becton Dickinson, Franklin Lakes, New Jersey) at $37^{\circ} \mathrm{C}$ for 48 hours. The resulting concentration was $3.7 \times 10^{4} \mathrm{CFUs} / \mathrm{ml}$. Both devices used sterile saline solutions in their integrated irrigation systems.

Contamination was assessed by placing 48 Petri dishes containing mannitol salt agar (Merck, Darmstadt, Germany) at the table height $(100 \mathrm{~cm})$ at even intervals over an area of $6 \times 8$ metres. The dishes were opened immediately before starting to remove the cement and closed five minutes after completion of the test in order to allow for complete settling of the aerosol. This gave a total exposure time of $40 \mathrm{~min}-$ 
utes. We also obtained body and face contamination cultures from all team members. After incubation at $37^{\circ} \mathrm{C}$ for 48 hours any micro-organisms present on the Petri dishes were differentiated by morphological, physiological and serological criteria. For identification of Staphylococcus aureus we used both a commercial test kit (Pastorex Staph Plus; Sanofi Pasteur Diagnostics, Chaska, Minnesota) and the classical tube coagulation test, calculating the median CFU counts from the repeated tests.

\section{Results}

We detected environmental contamination throughout the room $(6 \times 8 \mathrm{~m})$ after the use of both tools (Fig. 1). The ultrasound device showed a lower number of CFUs and no bacterial growth in some of the dishes, but there was growth in some of the most remote dishes at the borders of the room. The high-speed cutter contaminated all dishes with a high number of CFUs in all areas.

For body contamination the ultrasound device produced a lower number of CFUs in the surveillance cultures, but both devices contaminated all members of the surgical team to some extent (Fig. 2). The anaesthetist was least contaminated. The patient's head, although protected by the drape, also showed contamination. The $95 \%$ confidence intervals (CI) demonstrated a significant difference between the two methods with the upper level produced by the ultrasound device being considerably less than the lower level produced by the high-speed cutter.

\section{Discussion}

There are two distinct aspects to the risk of infection from an environment which is contaminated by aerosols. The first is the contamination of health-care workers in the operating room either directly through the aerosol cloud or by contact with contaminated instruments or surfaces. There are several reports of infection from bacterial agents such as Staphylococcus aureus and viral agents like hepatitis B and $\mathrm{C}$ and Herpes simplex from injuries with sharp and highspeed tools. ${ }^{7-11}$ There is also a risk of infection for team members through inhalation of aerosols contaminated with pathogens such as Mycobacterium tuberculosis, legionella, hepatitis B, varicella zoster, smallpox, influenza and Staphylococcus aureus. ${ }^{12,13}$

The second is a risk of infection for patients operated on in the same room after such surgery or in contact with contaminated medical staff. Evidence for such a route of transmission has been reported by Isenberg et $\mathrm{al}^{14}$ for a singlesource outbreak transmitted through a scrub nurse with positive cultures of Candida tropicalis on her fingertips and in her nasopharynx. Other bacterial and viral agents can survive on surfaces in the operating room and then be transmitted by way of medical personnel and instruments. ${ }^{15}$

Both devices for removal of cement contaminated all individuals in the operating room to some extent. Suffi- cient personal protection, consisting of water-resistant surgical gowns with long sleeves, gloves and full-face protection with face shields should be mandatory during these operations. Protection should be worn by everyone in the room including the anaesthetist, not only throughout the procedure, but afterwards until the room has been disinfected.

The aerosol produced by both devices covered an area of $6 \times 8 \mathrm{~m}$, the whole operating room workspace. The number of CFUs differed for the two devices, with the ultrasound device producing much lower numbers. This may have been due to the high temperatures of over $100^{\circ} \mathrm{C}$ which were recorded during the use of this device; some of the most remote dishes were, however, contaminated. Although a lower number of CFUs means a lower chance of infection, there remains a risk. The extent, concentration and risk of infection were higher with the hand-guided high-speed cutter.

We simulated blood flow and blood loss comparable to those of a revision hip arthroplasty as simulation directly through the vessels of a cadaver is not possible. While the simulation of blood flow which is produced by placing needles in the soft tissues surrounding the femur and into the femoral cavity may be a limitation of the model, we believe that our results are comparable to those of a real procedure. A concentration of 2 to $4 \times 10^{4} \mathrm{CFUs} / \mathrm{ml}$ in the fluid gave a realistic simulation of an infected patient, since such and even higher plasma levels of infectious agents are found in vivo. ${ }^{16}$ Staphylococcus aureus was chosen as the example micro-organism because it is easily detectable. The use of a human cadaver meant that the surgical procedure was realistic and all draping and clothing were those routinely used in the orthopaedic operating theatre.

We propose that effective measures of body protection for all personnel during revision arthroplasty should be introduced. ${ }^{3,17}$ Only a minimum number of people, all trained in the appropriate safety procedures, should be present in the operating room. Air filtration in the operating theatre may lead to improved safety of the personnel and the patient. We also recommend that patients with proven infections are operated on at the end of the day and that the operating theatre is efficiently disinfected after all removal of cement using ultrasound devices or high-speed cutters. ${ }^{1}$

No benefits in any form have been received or will be received from a commercial party related directly or indirectly to the subject of this article.

\section{References}

1. Nogler M, Lass-Florl C, Ogon M, et al. Environmental and body contamination through aerosols produced by high-speed cutters in lumbar spine surgery. Spine 2001;26:2156-9.

2. Nogler M, Lass-Florl C, Wimmer C, et al. Aerosols produced by highspeed cutters in cervical spine surgery: extent of environmental contamination. Eur Spine J 2001;10:274-7.

3. Nogler M, Wimmer C, Lass-Florl C, et al. Contamination risk of the surgical team through ROBODOC's high-speed cutter. Clin Orthop 2001;387:225-31.

4. Giachino AA, Profitt AW, Taine W. Expected contamination of the orthopedic surgeon's conjunctiva. Can J Surg 1988;31:51-2. 
5. Giachino A, Profitt A, Taine W. Contamination of the conjunctiva of the orthopaedic surgeon: a technical note. J Bone Joint Surg [Am] 1988;70-A:126-7.

6. Gardiner R, Hozack WJ, Nelson C, Keating EM. Revision total hip arthroplasty using ultrasonically driven tools: a clinical evaluation. $J$ Arthroplasty 1993;8:517-21.

7. Quebbeman EJ, Telford GL, Hubbard S, et al. Risk of blood contamination and injury to operating room personnel. Ann Surg 1991;2145:614-20.

8. Hadler SC. Hepatitis B virus infection and health care workers. Vaccine 1990;8 Suppl: S24-8.

9. Harpaz R, Von Seidlein L, Averhoff FM, et al. Transmission of hepatitis B virus to multiple patients from a surgeon without evidence of inadequate infection control. N Engl J Med 1996;334:549-54.

10. Epstein JB, Rea G, Sibau L, Sherlock CH. Rotary dental instruments and the potential risk of transmission of infection: herpes simplex virus. J Am Dent Assoc 1993;124:55-9.
11. Hauman CH. Cross-infection risks associated with high-speed dental handpieces. J Dent Assoc S Afr 1993;48:389-91.

12. Legnani P, Checchi L, Pelliccioni GA, D'Achille C. Atmospheric contamination during dental procedures. Quintessence Int 1994;25:435-9.

13. Eickhoff TC. Airborne nosocomial infection: a contemporary perspective. Infect Control Hosp Epidemiol 1994;15:663-72.

14. Isenberg HD, Tucci V, Cintron F, et al. Single-source outbreak of Candida tropicalis complicating coronary bypass surgery. J Clin Microbiol 1989;27:2426-8

15. Talon D. The role of the hospital environment in the epidemiology of multi-resistant bacteria. J Hosp Inf 1999;43:13-7.

16. Piatak M Jr, Saag MS, Yang LC, et al. High levels of HIV-1 in plasma during all stages of infection determined by competitive PCR. Science 1993;259:1749-54.

17. Wong DA, Jones AA, Lange K. Risk of blood contamination of health care workers in spine surgery: a study of 324 cases. Spine 1998;23:12616. 